\title{
Adsorption of citrate ions on hydroxyapatite synthetized by various methods
}

\author{
E. Skwarek $\cdot$ W. Janusz $\cdot$ D. Sternik
}

Received: 24 July 2013/Published online: 22 November 2013

(c) The Author(s) 2013. This article is published with open access at Springerlink.com

\begin{abstract}
The specific adsorption of citric acid ions at hydroxyapatite interface was investigated by the means of radioisotope method $\left({ }^{14} \mathrm{C}\right)$ as a function of citric acid ions concentration, $\mathrm{NaCl}$ concentration and $\mathrm{pH}$. Application of the hydroxyapatite has become wide in the biomaterial field as the $\mathrm{Ca}_{10}(\mathrm{OH})_{2}\left(\mathrm{PO}_{4}\right)_{6}$ possess biocompatibility with human hard tissue. Hydroxyapatite was synthesized using three different methods. The physical properties of the resulting powder were characterized by DTA/TG, XRD, AFM and SEM microscopy. Physicochemical qualities characterizing the electrical double layer of the hydroxyapatite $/ \mathrm{NaCl}$ solution interface were determined. The zeta potential and the adsorption of citric acid molecule were studied as a function of $\mathrm{pH}$. The point of zero charge and the isoelectric point of samples were determined. Electrical double layer parameters of hydroxyapatite $/ \mathrm{NaCl}$ interface are influenced by a synthesis method. The points $\mathrm{pH}_{\mathrm{pzc}}$ and $\mathrm{pH}_{\text {IEP }}$ for sample 1 are $\mathrm{pH}_{\mathrm{pzc}} 7.5$ and $\mathrm{pH}_{\text {IEP }} 3$; for sample 2 $\mathrm{pH}_{\mathrm{pzc}} 7.05$ and $\mathrm{pH}_{\mathrm{IEP}} 3$, for smaple $3 \mathrm{pH}_{\mathrm{pzc}} 6.7$ and $\mathrm{pH}_{\mathrm{IEP}}$ 3. Temperature has weak influence both on pure substance and with citric acid adsorbed, as derivatographic analysis has shown, and characterization of hydroxyapatite structure may be carried out by this thermal analysis. Two phenomena are responsible for citric acid adsorption: phosphate group's replacement at hydroxyapatite surface by citric ions parallel to intraspherical complexes formation.
\end{abstract}

Paper presented during the 6th all Polish Conference on Radiochemistry and Nuclear Chemistry, Krakow (Poland), 21-24.04.2013.

E. Skwarek $(\bowtie) \cdot$ W. Janusz · D. Sternik

Faculty of Chemistry, Maria Curie-Sklodowska University, Maria Curie-Sklodowska Sq. 5, 20-031 Lublin, Poland

e-mail: ewunias@hektor.umcs.lublin.pl
Keywords Hydroxyapatite · Adsorption · Citric acid . Thermal analysis

\section{Introduction}

Hydroxyapatite $\left[\mathrm{Ca}_{10}(\mathrm{OH})_{2}\left(\mathrm{PO}_{4}\right)_{6}\right]$ has been studied for many years, due to its occurrence in natural environment and practical application. As a natural mineral it is present in igneous and metamorphic rocks. Moreover, it is a major inorganic component of bones and teeth. Calcium phosphate and calcium carbonate are human hard tissues constituents, with the same structure as the natural mineral. Thanks to its crystallographic similarity with natural bone minerals, biocompatibility with hard tissues and with skin or muscle tissues, bioactivity, no toxicity, and implants made of synthetic hydroxyapatite (bioceramic hydroxyapatite) are used as an artificial bone substitute in orthopedic, neurosurgery, dental surgery, plastic surgery and dental applications [1-4].

Methods of hydroxyapatite preparation may have influence on specific chemical properties of adsorbent surface. High purity and desirable microstructure of hydroxyapatite have been obtained using the processes: sol-gel, co-precipitation, microemulsion synthesis or hydrothermal reactions [5]. The study of the electrical double layer structure for the hydroxyapatite/electrolyte solution interface reveal that the $\mathrm{pH}_{\mathrm{pzc}}$ and $\mathrm{pH}_{\text {iep }}$ data lie in a wide range, from 4.35 for dental hydroxyapatite up to 8.6 for synthetic samples, and it is very difficult to compare them. The main reason for this is the fact that all experimental results were obtained for hydroxyapatite samples of different origin, stoichiometry and purity, under various experimental conditions, and by different experimental techniques. However, the solubility of hydroxyapatites should be taken 
into account in determination of surface charge density and $\mathrm{pH}_{\mathrm{pzc}}$ by means of potentiometer titration. The studies of the electrical double layer at the hydroxyapatite/electrolyte solution interface show that besides $\mathrm{Ca}^{2+}$ and phosphate, $\mathrm{H}^{+}$and $\mathrm{OH}^{-}$are potential determining ions [6, 7]. The charge on hydroxyapatite arises as a result of various reactions of surface hydroxyl groups and unequal adsorption from solution of ions of opposite charges [8-10]. Because hydroxyapatite is a basic salt, there are two types of groups on the surface: hydroxyl and phosphatic. There is no doubt that the phosphatic groups have more acidic character than hydroxyl ones, which are of alkaline character. The reactions of surface groups at the hydroxyapatite that create surface charge are following:

$$
\begin{aligned}
& \equiv \mathrm{CaOH}+\mathrm{H}^{+} \rightleftarrows \equiv \mathrm{CaOH}_{2}^{+} \\
& \equiv \mathrm{CaOH} \rightleftarrows \equiv \mathrm{CaO}^{-}+\mathrm{H}^{+} \\
& \equiv \mathrm{PO}_{4} \mathrm{H} \rightleftarrows \equiv \mathrm{PO}_{4}^{-}+\mathrm{H}^{+} \\
& \equiv \mathrm{PO}_{4}^{-}+\mathrm{Ca}^{2+} \rightleftarrows \equiv \mathrm{PO}_{4}+\mathrm{Ca}^{2+} .
\end{aligned}
$$

The literature about sorption on hydroxyapatite using the isotope method includes the papers about adsorption of $\mathrm{Ni}, \mathrm{Cu}$, and $\mathrm{Sr}$ written by Rosskopfova et al. [11-13]. However of no less importance are problems related with anions, among others, citrate anions.

The adsorption process of citric acid on the surface of hydroxyapatite was described by Filgueiras, Mkhonto and de Leeuw using the computer modelling method. The structure and energy of the hydroxyapatite and citric acid complex was determined thanks to interatomic potentials. There was a series of computer simulations performed to investigate the adsorption of citric acid on different surfaces of hydroxyapatite. They showed that the intensity of the acid particle influence on the surface is conditioned by stability of the surface and possibility of repeated interaction of an acid molecule with the active adsorption places of hydroxyapatite, especially with two or more calcium atoms. Big adsorption energy causes the citric acid adsorption on the surface of hydroxyapatite to be exceptionally strong. Therefore it can be concluded that citric acid should serve as a good inhibitor for the hydroxyapatite increase if we look at it as to be used in the synthesis. Blocking the active places on the surface of hydroxyapatite inhibits the increase of its crystal [14].

While investigating the citric acid adsorption on hydroxyapatite, Vega, Narda and Ferreti [15] explained the process in a following way. The adsorption process occurred through the exchanges of phosphate groups with citrate anions. The adsorption isotherm equalled the Langmuir isotherm. The complex of citric acid and hydroxyapatite originated from combining one molecule of citric acid with two active places of hydroxyapatite. It was confirmed during research that the active places on the surface of hydroxyapatite are not equal and the surface itself is not uniform. The special structure of hydroxyapatite caused the fact that, the possibility of the ions adsorption depends on the occupied neighbouring spaces. In connection to that the adsorption of the first layer of citrate at the hydroxyapatite/nonelectrolyte solution interface can be treated as monolayer adsorption and the next layers become a part of the solution itself. As Lopez-Macipe, Gomez-Moralez and Rodriguez-Clemente [16] explain in their work, the adsorption of citric acid on hydroxyapatite depends to a great extent on $\mathrm{pH}$ value. However, the mechanism of interactions between citric acid and hydroxyapatite is not completely clear. There is a theory which states that citric acid ions influence hydroxyapatite through ionic exchange between phosphate groups and citrate ions. In reactions between citrate ions and hydroxyapatite, $\mathrm{pH}$ value has a crucial value because it determines the kinds of citric ions capable of adsorption on the hydroxyapatite surface. According to the authors' assumptions citrate ions can have different forms e.g. $\mathrm{Cit}^{3-}$, $\mathrm{HCit}^{2-}$ and $\mathrm{H}_{2} \mathrm{Cit}^{-}$. The dependence was determined on the basis of the analysis concerning the citrate ions on hydroxyapatite at of 25 and $37^{\circ} \mathrm{C}$. Amount of citric ions adsorbed was different in examined solutions because of different $\mathrm{pH}$ values. At $\mathrm{pH}$ value 6 the dominating form were $\mathrm{H}_{2} \mathrm{Cit}^{-}$ions whereas at $\mathrm{pH}$ value 8 there was the highest concentration of $\mathrm{Cit}^{3-}$ ions. The adsorption process of citric acid on hydroxyapatite with low concentration of citric acid was described using the Langmuir adsorption model. This adsorption occurs here through replacement of the phosphate ions by citrate ions on the solid substance/solution interface. This is a result of higher relation of citrate ions to the hydroxyapatite surface. Presence of different forms of citrate ions caused different types of interactions. $\mathrm{Cit}^{3-}$ ions react in a two-donor way (1 citrate ion occupies 2 sites of $\mathrm{Ca}$ ) and reactions of $\mathrm{HCit}^{2-}$ ions are stronger than the previous one (1 citrate ion replaces $1 \mathrm{Ca}$ ). Such dependence is possible owing to the resonance between the monodonor (using one group $-\mathrm{COO}^{-}$) and the surface of chelation (using two groups $-\mathrm{COO}^{-}$).To sum up, the adsorption decreases with the growth of $\mathrm{pH}$ value. Despite that the experiments showed that at $\mathrm{pH} 6$ it is higher than in a solution at $\mathrm{pH} 8$ [17]. Chemical reactions between citric acid and hydroxyapatite in a human body have many consequences. The first one is partial dissolution of apatite, another one is precipitation of calcium citrate occurring when the concentration of the acid is over $10 \mathrm{mmol} / \mathrm{dm}^{3}$. According to Misra, interactions between citric acid and hydroxyapatite can be called chemical reactions. However, the exchange with phosphate ions is responsible for the adsorption of citrate ions. This is confirmed by short time of the balancing process during the 
reaction of citrate salts of alcaline metals with hydroxyapatite. The literature has largely demonstrated that the synthesis routes and related parameters could significantly affect not only hydroxyapatite particle size and morphology, but also phase composition, thermal stability as well as sintering behavior [18].

The information available in the literature concerning hydroxyapatite focuses mainly on two issues: thermal analysis of hydroxyapatite and electrochemical properties analysis. This work is combination of these two scientific currents using the example of hydroxyapatites obtained in three different syntheses, which makes a wider view possible on hydroxyapatite as biomaterial used by the human body. The goal of this paper is characterization of hydroxyapatite, determination of $\mathrm{pH}_{\mathrm{pzc}}$ and $\mathrm{pH}_{\text {iep }}$ points, establishing zeta potential depending on $\mathrm{pH}$. The specific adsorption of citric acid ions at the hydroxyapatite interface was investigated. The main part of the study was to investigate the thermal effects: caused by citric acid sorption on hydroxyapatite and methods of hydroxyapatite preparation.

\section{Materials and method}

The investigated adsorbents were synthesized by three wet methods [2-4].

In this paper hydroxyapatite was prepared using three methods:

\section{Method 1 [2]}

$$
10 \mathrm{Ca}(\mathrm{OH})_{2}+6 \mathrm{H}_{3} \mathrm{PO}_{4} \rightarrow \mathrm{Ca}_{10}\left(\mathrm{PO}_{4}\right)_{6}(\mathrm{OH})_{2}+18 \mathrm{H}_{2} \mathrm{O}
$$

In the reaction there were used the following reagents: Calcium hydroxide $\mathrm{Ca}(\mathrm{OH})_{2}$ produced by Aldrich and phosphoric acid $\mathrm{H}_{3} \mathrm{PO}_{4}(\mathrm{~V})$ made by $\mathrm{POCh}$ Gliwice. There were prepared $1 \mathrm{M}$ aqueous solutions with reagents, $0.3 \mathrm{dm}^{3}$ of phosphoric acid and $0.18 \mathrm{dm}^{3}$ of calcium base were used in the reaction. The $\mathrm{H}_{3} \mathrm{PO}_{4}$ solution was dropped into the $\mathrm{Ca}(\mathrm{OH})_{2}$ suspension placed in the flask for $15 \mathrm{~min}$. During dropping in the reaction mixture was stirred vigorously and then dried in a dryer for $24 \mathrm{~h}$. A white sediment of the crystalline structure of hydroxyapatite was obtained. Then the sediment was washed with redistilled water till the constant value of redistilled water conductivity was achieved.

\section{Method 2 [3]}

In the reaction there were used the following reagents: calcium acetate $\left(\mathrm{CH}_{3} \mathrm{COO}\right)_{2} \mathrm{Ca}$ from Fluka and dipotassium hydrophosphate $\mathrm{K}_{2} \mathrm{HPO}_{4}$ from POCh, Gliwice. The solutions of concentrations $0.1 \mathrm{M} \mathrm{K}_{2} \mathrm{HPO}_{4}$ and $0.06 \mathrm{M}$ $-\left(\mathrm{CH}_{3} \mathrm{COO}\right)_{2} \mathrm{Ca}$ were prepared. In the reaction there was taken $0.15 \mathrm{dm}^{3}$ of each salt and both solutions were dropped into $0.2 \mathrm{dm}^{3}$ of water placed in the reaction flask. The flask was immersed in a water bath heated up to $100{ }^{\circ} \mathrm{C}$. The salt solutions were dropped in at the same time for $30 \mathrm{~min}$ and then the reaction mixture was boiled for $1 \mathrm{~h}$. The mixture was stirred vigorously and the constant temperature was kept all the time. The obtained sediment was washed with redistilled water till the constant value of redistilled water conductivity was achieved.

Method 3 [4]

$\quad 6 \mathrm{CaHPO}_{4} \cdot 2 \mathrm{H}_{2} \mathrm{O}+4 \mathrm{Ca}(\mathrm{OH})_{2}$
$\quad \rightarrow \mathrm{Ca}_{10}\left(\mathrm{PO}_{4}\right)_{6}(\mathrm{OH})_{2}+18 \mathrm{H}_{2} \mathrm{O}$.

Synthetic hydroxyapatite was prepared hydrothermally according to the reaction

In order to prepare hydroxyapatite there was applied the following procedure: $1.0324 \mathrm{~g}$ of $\mathrm{CaHPO}_{4} * 2 \mathrm{H}_{2} \mathrm{O}$ from Fluka and $0.2964 \mathrm{~g}$ of $\mathrm{Ca}(\mathrm{OH})_{2}$ from Aldrich were taken and mixed. $80 \mathrm{ml}$ of double distilled water was poured in and the $\mathrm{pH}$ value was reduced to 9 using $80 \%$ analytically pure acetic acid from $\mathrm{POCh}$. The reaction mixture was put into a drier for $24 \mathrm{~h}$ at $120{ }^{\circ} \mathrm{C}$. The obtained hydroxyapatite had to be purified from reagents so the sediment was washed many times with redistilled water and centrifuged.

Hydroxyapatite was investigated using X-ray diffraction (XRD), adsorption-desorption of nitrogen accelerated surface area and porosimetry (ASAP2405, Micromeritics Instruments, Co.), photon correlation spectroscopy (PCS), AFM and SEM microscopes. The classical thermogravimetric (aparatQ-1500D type made by MOM, Budapest, Hungary) TG and DTG curves of thermal analysis, which gave the dependence of the weight loss of a sample as a function of temperature or time, were measured over a temperature range from 20 to $1,000{ }^{\circ} \mathrm{C}$ with a furnaceheating rate of $10^{\circ} \mathrm{C} / \mathrm{min}$. The TG and DTG curves were registered digitally under the control of the program Derivat running on PC.

The specific adsorption of citric acid ions at the hydroxyapatite interface was investigated by the means of the radioisotope method as a function of citric acid ions concentration, $\mathrm{NaCl}$ and $\mathrm{pH}$. The initial concentration of citric acid ions ranged from $1 \times 10^{-6}$ to $1 \times 10^{-3} \mathrm{~mol} \mathrm{dm}^{-3}, \mathrm{pH}$ was changed from 6 to 12 . As a background electrolyte $\mathrm{NaCl}$ solution was used of the concentrations $0.001 \mathrm{~mol} \mathrm{dm}^{-3}$. The adsorption measurements were complemented by the potentiometric titration of hydroxyapatite suspensions and electrophoresis measurements. 
To remove ionic type contaminations, which might influence the ion adsorption measurements, the hydroxyapatite was washed with double distilled water until constant conductivity about $0.5 \mu \mathrm{S} / \mathrm{cm}$ was achieved. Adsorption and surface charge measurements were performed simultaneously in the suspension of the same solid content, to keep the identical conditions of the experiments in a thermostated Teflon vessel at $25^{\circ} \mathrm{C}$. To eliminate the influence of $\mathrm{CO}_{2}$ all potentiometric measurements were performed under nitrogen atmosphere. $\mathrm{pH}$ values were measured using a set of glass REF 451 and calomel pHG201-8 electrodes with the Radiometer assembly. Surface charge density was calculated from the difference of the amounts of added acid or base to obtain the same $\mathrm{pH}$ value of suspension as for the background electrolyte.

The zeta potential of hydroxyapatite dispersions was determined by electrophoresis with Zetasizer 3000 by Malvern. The measurements were performed at $100 \mathrm{ppm}$ solid concentration ultrasonication of the suspension.

\section{Results and discussion}

The specific surface of the hydroxyapatite samples was obtained by adsorption-desorption of nitrogen. Table 1 presents the structural parameters of hydroxyapatite. On the basis of the results in Table 1 , the difference in the surface area and average volume of pores can be seen. The surface area and average volume of pores of sample 1 are greater than those of samples 2 and 3. The analyzed samples of hydroxyapatite have mesopores, a significant difference in the size of the surface itself, which confirms the influence of the synthesis method, can be also observed.

Figure 1 shows the AFM micrographs of several hydroxyapatite samples 1,2 , and 3 . The examination with

Table 1 Chosen structural parameters, sample 1, sample 2 and sample 3

\begin{tabular}{|c|c|c|c|}
\hline & Sample 1 & Sample 2 & Sample 3 \\
\hline BET surface area $(\mathrm{m} 2 / \mathrm{g})$ & 86.15 & 34.42 & 26.34 \\
\hline Langmuir surface area $(\mathrm{m} 2 / \mathrm{g})$ & 109.91 & 44.25 & 33.71 \\
\hline $\begin{array}{l}\text { BJH cumulative adsorption surface } \\
\text { area of pores between } 1.7 \text { and } \\
300 \mathrm{~nm} \text { diameter }(\mathrm{cm} 3 / \mathrm{g})\end{array}$ & 0.51 & 0.14 & 0.13 \\
\hline $\begin{array}{l}\text { BJH cumulative desorption surface } \\
\text { area of pores between } 1.7 \text { and } \\
300 \mathrm{~nm} \text { diameter }(\mathrm{cm} 3 / \mathrm{g})\end{array}$ & 0.50 & 0.13 & 0.12 \\
\hline $\begin{array}{l}\text { Average pore diameter ( } 4 \text { V/A by } \\
\text { BET })(\mathrm{nm})\end{array}$ & 18.81 & 12.24 & 15.08 \\
\hline $\begin{array}{l}\text { BJH adsorption on average pore } \\
\text { diameter }(4 \text { V/A) }(\mathrm{nm})\end{array}$ & 20.82 & 13.55 & 15.75 \\
\hline $\begin{array}{l}\text { BJH desorption on average pore } \\
\text { diameter }(4 \text { V/A) }(\mathrm{nm})\end{array}$ & 19.08 & 13.48 & 8.39 \\
\hline
\end{tabular}

an AFM microscope confirms the porosity of the synthesized hydroxyapatites samples of surface. At the pictures you can see the structures built from little crystals with visible pores. Topographic analysis of the hydroxyapatite samples shows that the surface of sample 2 is rougher, the average roughness index is 44 whereas for sample 1 it is 30.4 and for sample 3-21.28. The average roughness for sample 2 is $172 \mathrm{~nm}$, for sample $1-149 \mathrm{~nm}$ and for sample 3-142 nm. Sample 2 exhibited the formation of whisker morphologies.

A crystallographic structure of samples was determined by XRD using the DRON-3 diffractometer using $\mathrm{CuK}_{\alpha}$ radiation. The XRD data depicted in Fig. 2 confirms phase purity of the studied samples. On diffractograms of the samples you can observe peaks characteristic for crystallic form of hydroxyapatite, i.e. peaks and their intensities occurring at the angles: $2 \theta: 25.9-35 \%$; 31.75-100\%; 32.96-55 \%; 39.84-20\%; 46.7-40\%; 49.5-30\%. Except for the peaks characteristic for hydroxyapatite you can observe some peaks confirming the occurrence of calcium carbonate $(2 \theta=29.4-100$ and $39.407-28 \%)$. The carbonate phase probably originated from repeated rinsing the sample with distilled water. A big adsorption affinity of the carbonate ions makes the obtained preparations often contain calcium carbonate [19]. The size of crystallites calculated with the Scherer's method from half width of the peak for the angle $2 \Theta=25.9$ was $36 \mathrm{~nm}$ for sample 3 , $48.4 \mathrm{~nm}$ for sample 2 and $28 \mathrm{~nm}$ for sample 1 . These results agree well with mentioned surface area measurements. Sample 3 has the largest crystallites, since it was prepared under acidic conditions.

On the basis of the photos taken with a scanning microscope (Fig. 3) one can see that in all cases, as a result of the synthesis, we get aggregations of hydroxyapatite molecules, whose sizes reach $20 \mu \mathrm{m}$, apart from them smaller molecules of sizes less than $1 \mu \mathrm{m}$ can be observed. From the sizes of crystallites determined on the basis of half width of XRD file we conclude that hydroxyapatite molecules consist of a huge number of crystals which connect creating a porous structure.

The surface charge density as a function of $\mathrm{pH}$ for studied samples in $0.001 \mathrm{M} \mathrm{NaCl}$ aqueous solution are depicted in Fig. 4 As it can be seen in the studied $\mathrm{pH}$ range the values surface charge density are negative, so pHpzc can be determined by extrapolation method. The obtained values for the samples are as follows 7.5 for sample 1, 7.05 for sample 2 and 6.7 for sample 3 . Additionally course of the dependence of surface charge density vs. $\mathrm{pH}$ shows that acidic properties of surface groups arranges in the following sequence sample $3>$ sample 2 sample1. These properties are results of the decreasing amount of calcium ions in the sample determined using EDAX method that is following 29.2 atom $\%$ for sample 1, 23.8 at.\% for sample 
Fig. 1 AFM micrograph of hydroxyapatite samples 1 (a), 2(b), 3(c) a

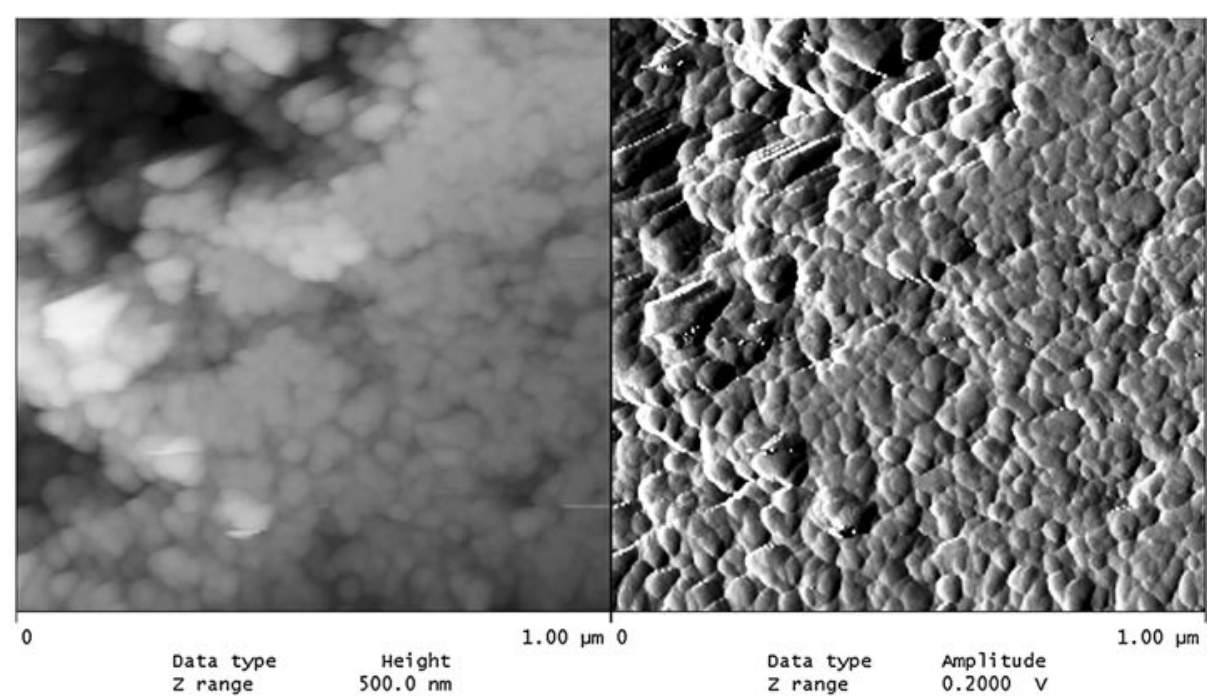

hap1.001

b

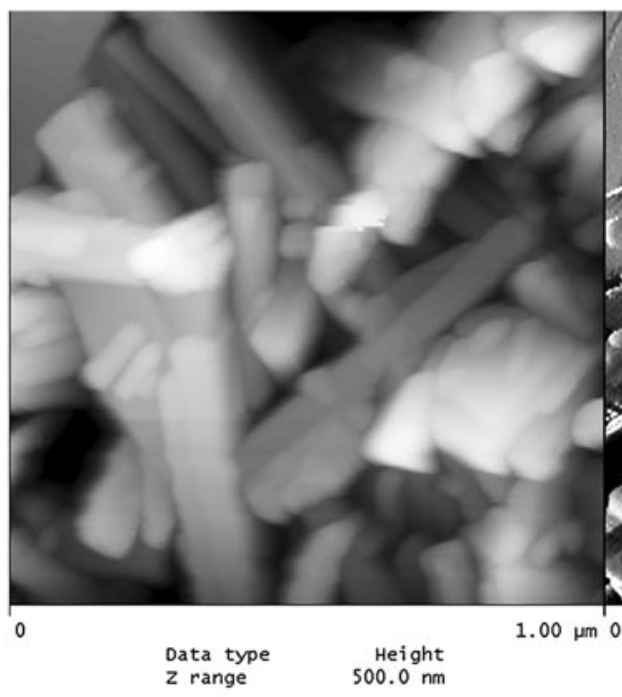

hap 2.000

c

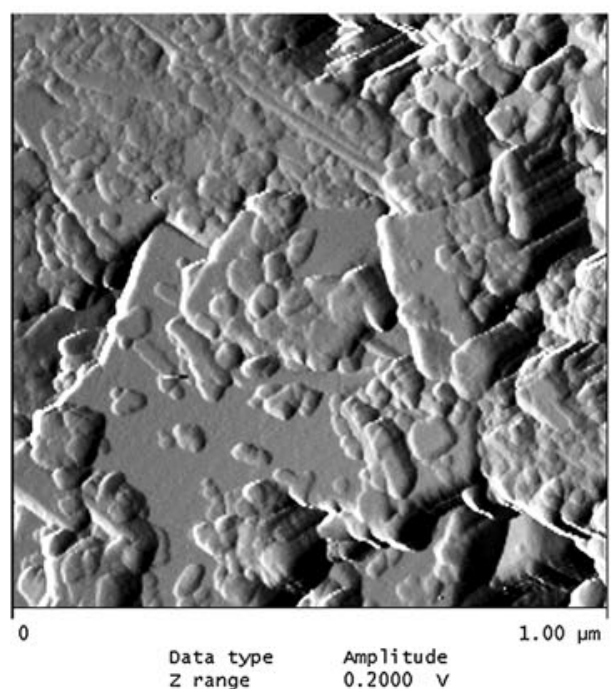




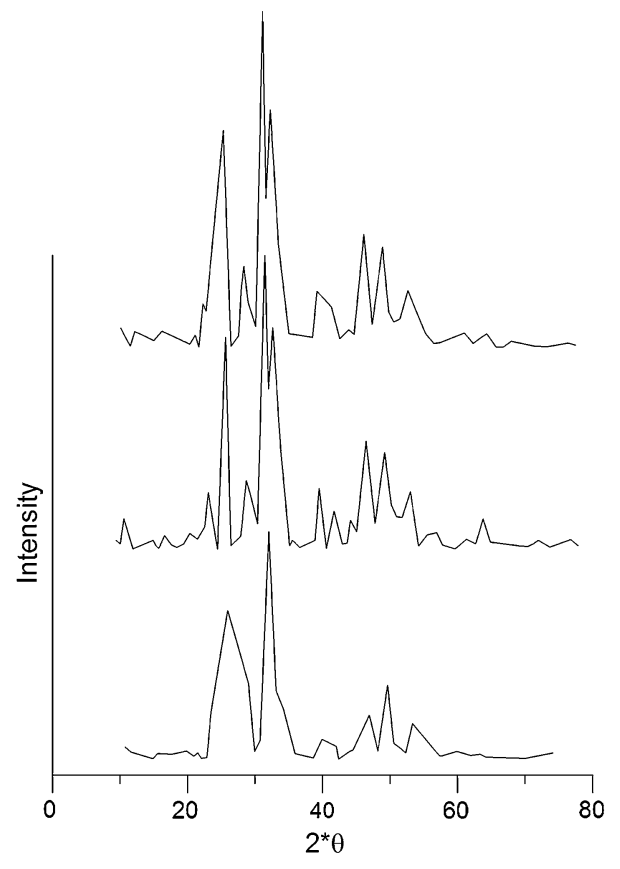

Fig. 2 Hydroxyapatite XRD

2 and 22.9 at.\% for sample 3. The increase of amount of calcium atoms in the sample lead to increase base properties of surface groups that is seen as a shift o pHpzc towards higher $\mathrm{pH}$.

The values are consistent with the literature [20].The course of dependence of $\zeta$ potential shows that zeta potential decreases with the increase in $\mathrm{pH}$ value for all the hydroxyapatite samples (Fig. 5). Extrapolation of the dependence of zeta potential in the $\mathrm{pH}$ function lets us assume that $\mathrm{pH}_{\text {IEP }}$ is about 4.3 for sample 3 so it is over 2 $\mathrm{pH}$ units lower than $\mathrm{pH}_{\mathrm{PZC}}$ for samples 2 and 1 is 3 so it is also lower than pHpzc of the examined samples because the zeta potential is additionally dependent on the part of surface load which is connected with adsorption and desorption of ions of the crystallic lattice: i.e. phosphate and calcium ions. There is a chemical interaction between citric acid and hydroxyapatite, the latter is the structural prototype for the principal inorganic crystalline constituent of teeth and bones.

Figure 6 presents dependence of citrate ions adsorption on hydroxyapatite $/ 0.001 \mathrm{~mol} / \mathrm{dm}^{3} \mathrm{NaCl}$ solution. As it can be seen the citrate adsorption does not reach $100 \%$ of pH in any of the initial concentrations. In lowest concentrations it reaches only $85 \%$ and that is why it is hard to establish parameters of the adsorption rim such as $\mathrm{pH}_{50} \%$ or $\mathrm{pH}_{10-90} \%$, because in the examined structure there is no adsorption envelope typical for specific anion adsorption. The proposed mechanism of citric acid adsorption on hydroxyapatite consists in replacing the phosphate ions with citrate ions. Dissociation constants of phosphoric acid
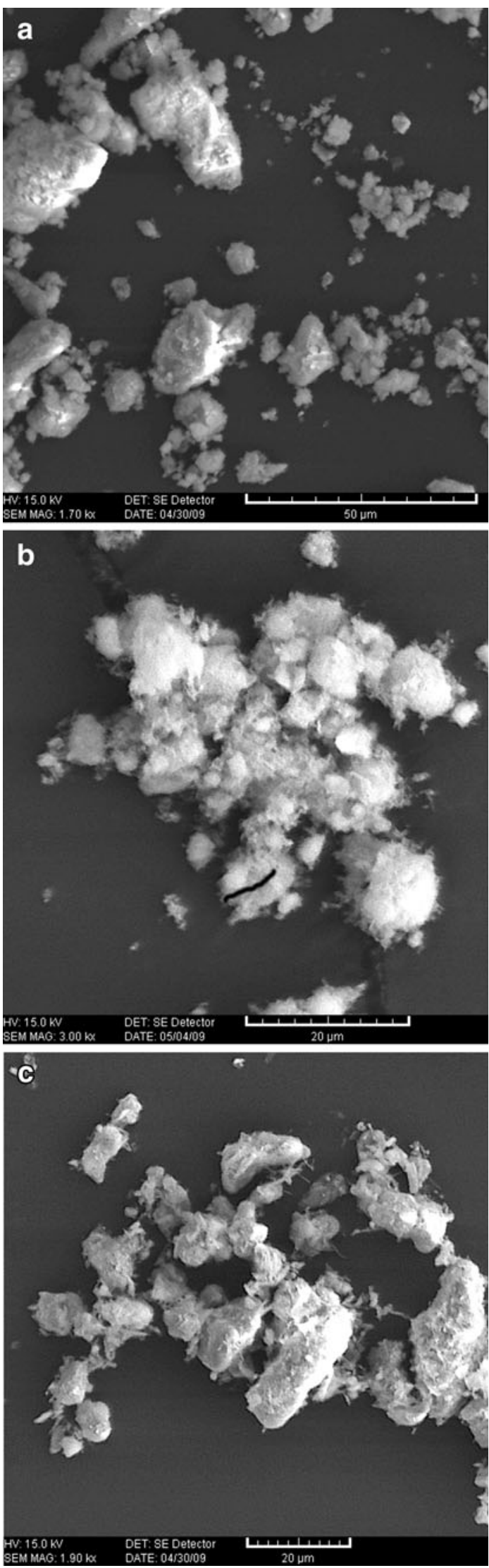

Fig. 3 SEM micrograph of hydroxyapatite samples 1 (a), 2(b), 3(c) 


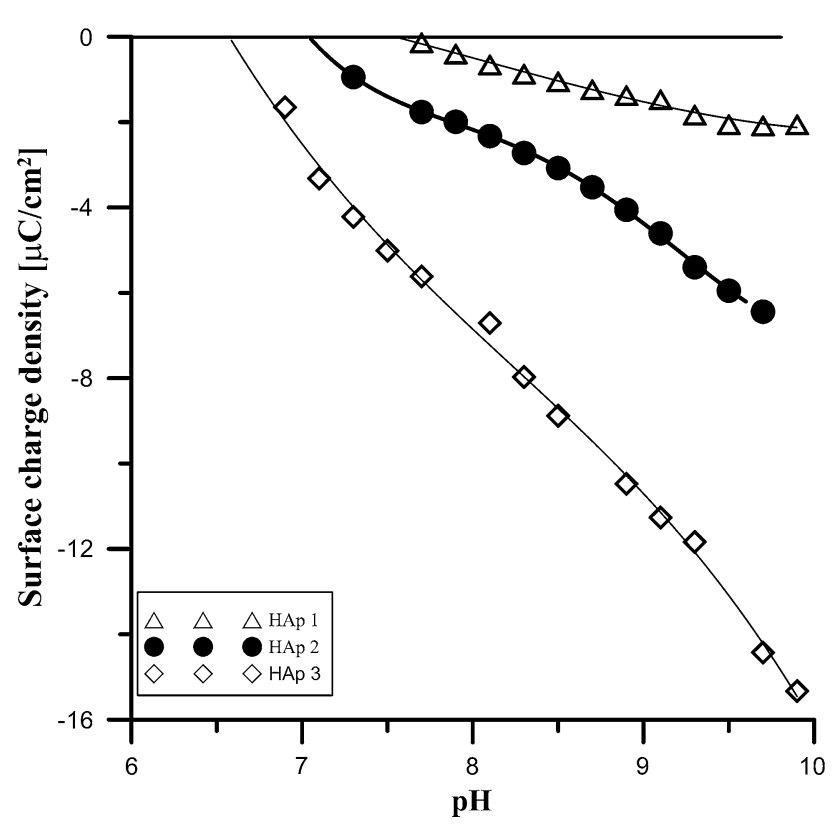

Fig. 4 The surface charge density $\mathrm{HAP} / \mathrm{NaCl}$ solution interface as a function of $\mathrm{pH}$ samples 1, 2, 3

$\mathrm{pK}_{\mathrm{a} 1}=2.83, \mathrm{pK}_{\mathrm{a} 2}=7.2 \mathrm{pK}_{\mathrm{a} 3}=11.9$ and citric acid $\mathrm{pK}_{\mathrm{a} 1}=3.13, \mathrm{pK}_{\mathrm{a} 2}=4.76 \mathrm{pK}_{\mathrm{a} 3}=6.40$, except for the first step are lower than the respective dissociation constants of citric acid. Therefore replacing the phosphate groups on the surface with the citrate groups will lead to the increase of the density of negatively charged groups on the hydroxyapatite surface. The mechanism of exchanging ions must be excluded because it should lead to a significant increase of negative charge as a result of the increase of citrate adsorption. The citrate ions definitely change the character of the surface of hydroxyapatite-they change its acidic character. Probably it is caused by the creation of the intraspherical complexes as a result of citrate adsorption.

The structural and adsorptive properties of hydroxyapatite depend on the modification method. Fig. 7 shows the thermogravimetric analysis of the samples synthesized with three methods (samples 1-a, 2-b, 3-c). On the basis of the TG and DTG curves you can conclude that as a result of heating the hydroxyapatite samples within the temperature range 20-950 ${ }^{\circ} \mathrm{C}$ you can distinguish two stages connected with the small weight loss from $3 \%$ for sample $3-5 \%$ for samples 1 and 2 . Within the temperature range $20-200{ }^{\circ} \mathrm{C}$ the weight loss with the minimum about $72{ }^{\circ} \mathrm{C}$ is connected with the endothermal process of removing the hygroscopic and physically adsorbed water. Within $200-950{ }^{\circ} \mathrm{C}$ small weight losses are connected with removing carbonates and structural water, chemically combined [21, 22]. The data is compatible with the results obtained by Bianco et al. [18] as well as Tonsueadn et al. [23]. Figures 8 and 9 present the comparison of the TG and DTG curves of the hydroxyapatite
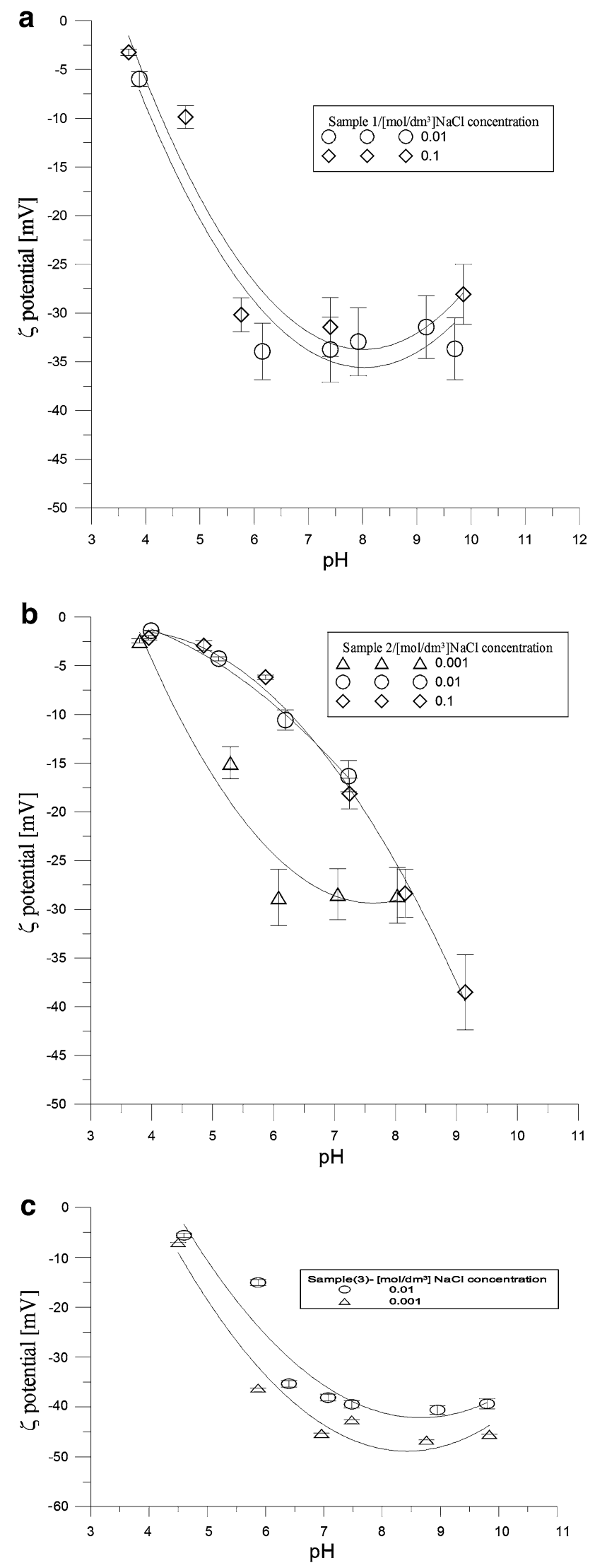

Fig. 5 Zeta potential of the hydroxyapatite $/ \mathrm{NaCl}$ solution interface as a function of $\mathrm{pH}$ samples 1 (a), 2(b), 3(c) 

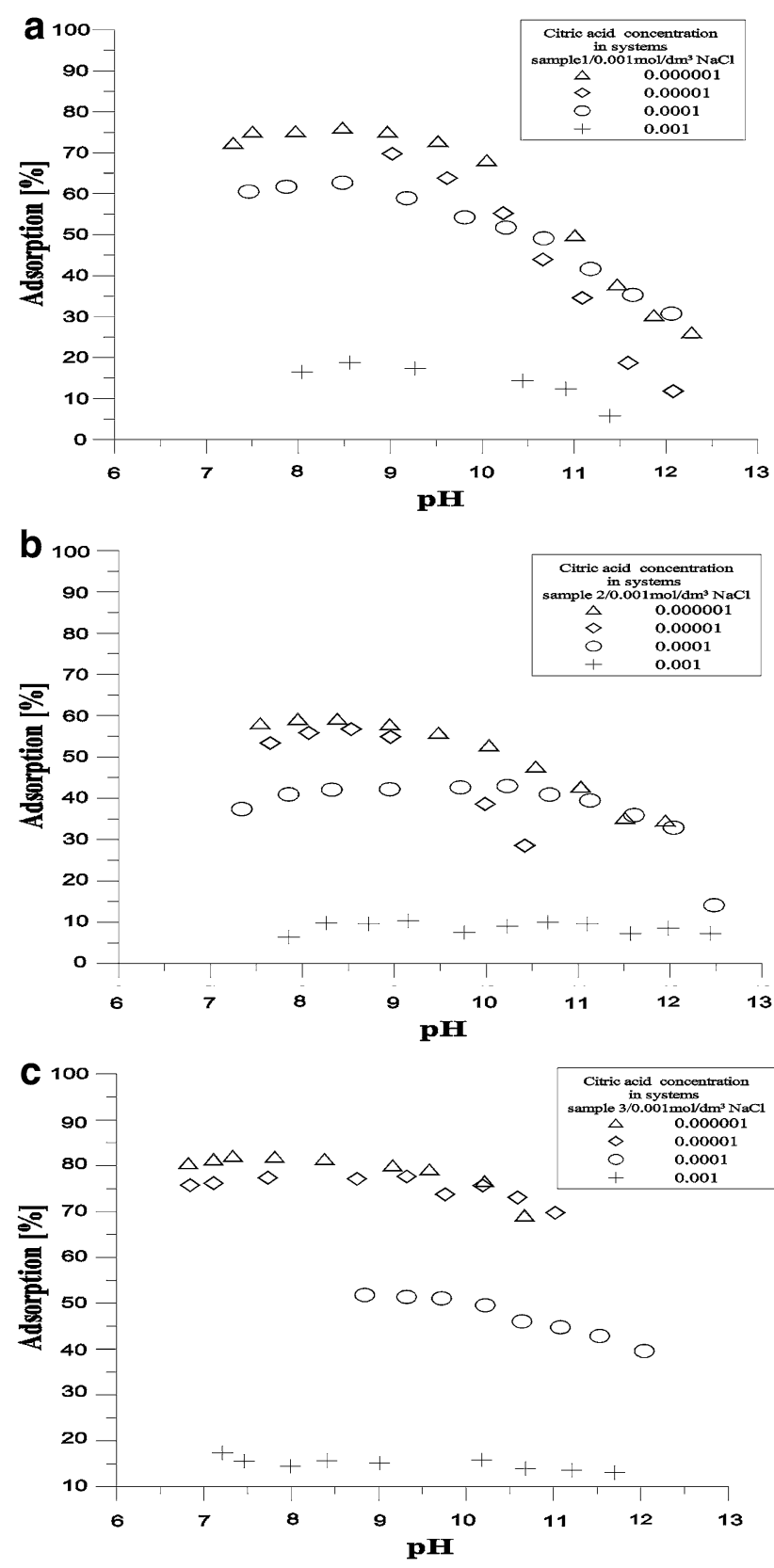

Fig. 6 Adsorption of citric acid samples 1 (a), 2(b), 3(c)

samples obtained by method 1 (Fig. 8) and method 2 (Fig. 9) and their samples modified with citric acid solution. Adsorption of citric acid on the hydroxyapatite surface changes not only the active centres on the surface and their energy but it also influences their thermal stability. These effects depend on the concentration of the modifier. In the case of the samples modified by the citric acid solution with $0.00001 \mathrm{M}$ concentration, the termogravimetric curves " $\mathrm{b}$ " are similar to those obtained for the base materials on the

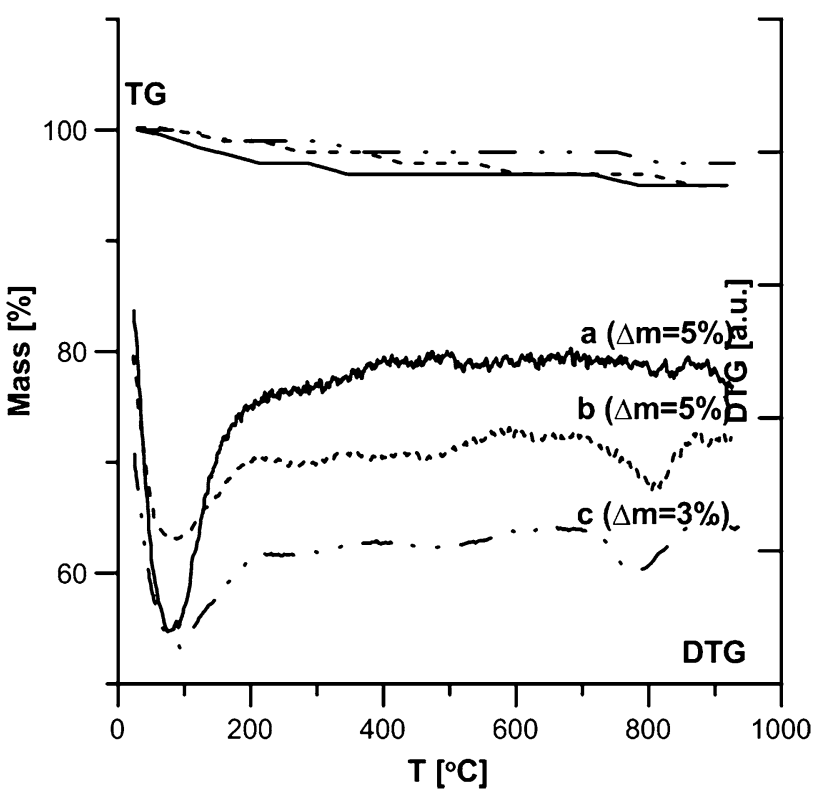

Fig. 7 DTA and DTG curves for hydroxyapatite

curve "a". The bigger peak on the DTG curve in the first part up to $200{ }^{\circ} \mathrm{C}$ in relation to pure hydroxyapatites is a sign of removal of the physically adsorbed water and the adsorbate molecules poorly connected with the surface. Evident changes of the DTG curves were observed in the case of modification with acid of $0.001 \mathrm{M}$ concentration. In this case there can be distinguished 3 stages of thermal dissolution -curve C (Figs. 8 and 9). The first stage is connected with removing water and poorly combined citric acid groups on the surface. In the second stage within the temperature range of $200-400{ }^{\circ} \mathrm{C}$ the weight loss on the TG curve is accompanied by an explicit peak on the DTG curve with minimal 292 for hydroxyapatite sample 1,307 for sample 2 is connected with precipitation and oxidation of strongly combined organic groups. In the temperature range $400-950{ }^{\circ} \mathrm{C}$ oxidation of organic coal to $\mathrm{CO}_{2}$ is observed. These changes are similar to the processes during the dissolution of citric acid complexes with metals [24]. This proves creating surface complexes between the molecules of acid and hydroxyapatite and the complexity of the entire process. The loss of intensity on the DTG curve in the temperature range 20-200 ${ }^{\circ} \mathrm{C}$ and the occurrence of the peak give evidence of the increase of the reaction intensity between the surface of hydroxyapatite and citric acid molecules. During DTG experiments a question arose if due to citric acid adsorption calcium citrate is created in reaction with calcium ions of the hydroxyapatite. Analysis of this problem has been carried out but it has been shown that there are too low citric acid concentrations to find it out but it is impossible to exclude such possibility. 


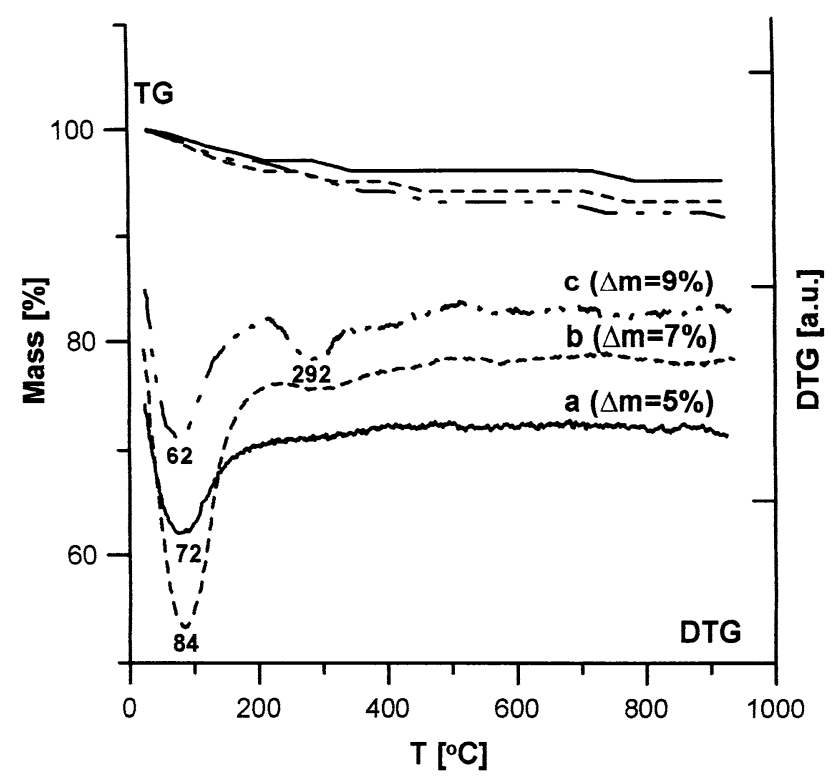

Fig. 8 DTA and DTG curves for hydroxyapatite with different citric acid concentrations

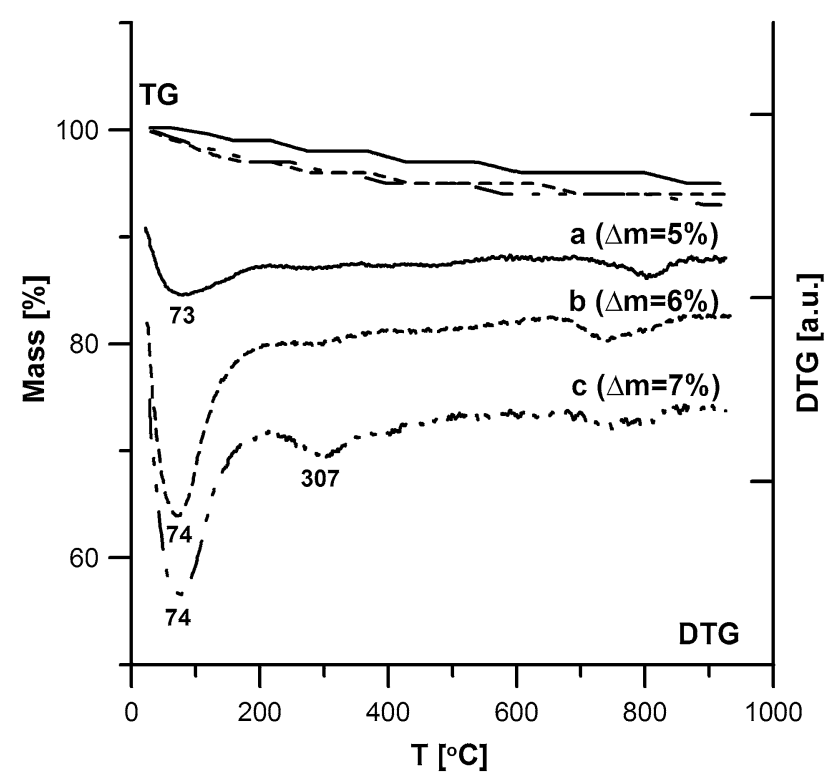

Fig. 9 The comparison DTA and DTG curves for hydroxyapatite and hydroxyapatite with citric acid

\section{Conclusions}

Hydroxyapatite was synthesized by three methods. The influence of synthesis methods on parameters of electrical double layer at the hydroxyapatite/ $\mathrm{NaCl}$ interface has been investigated. The results of XRD analysis and specific surface area obtained by AFM, SEM and BET indicate the relationship between the synthesis and edl parameters.
1. Investigations of the hydroxyapatite/electrolyte solution system are limited by dissolution of the minerals and $\mathrm{pH}$ range $7-11$.

2. The synthesis method influences the parameters of electrical double layer at hydroxyapatite $/ \mathrm{NaCl}$.

3. The points $\mathrm{pH}_{\mathrm{pzc}}$ and $\mathrm{pH}_{\mathrm{IEP}}$ for sample 1 are $\mathrm{pH}_{\mathrm{pzc}} 7.5$ and $\mathrm{pH}_{\mathrm{IEP}} 3$; for sample $2 \mathrm{pH}_{\mathrm{pzc}} 7.05$ and $\mathrm{pH}_{\mathrm{IEP}} 3$, for sample $3 \mathrm{pH}_{\mathrm{pzc}} 6.7$ and $\mathrm{pH}_{\mathrm{IEP}} 3$.

4. Derivatographic analysis has shown small influence of temperature on pure substance as well as with citric acid adsorbed, but that the thermal analysis can be used for characterization of structural hydroxyapatite.

5. The adsorption of citric acid occurs as a result of the replacement of the phosphate groups on the surface of hydroxyapatite with the citric ones together with the formation of the intraspherical complexes.

Open Access This article is distributed under the terms of the Creative Commons Attribution License which permits any use, distribution, and reproduction in any medium, provided the original author(s) and the source are credited.

\section{References}

1. Janusz W, Skwarek E, Złotucha A, Reszka M (2008) The electric double layer at the hydroxyapatite $/ \mathrm{NaClO}_{4}$ solution interface. Polish J Chem 82:57-67

2. Liu J, Ye X, Wang H, Zhu M, Wang B, Yan H (2003) The influence of $\mathrm{pH}$ and temperature on the morphology of hydroxyapatite synthesized by hydrothermal method. Ceram Int 29:629-633

3. Suzuki S, Ohgaki M, Ichiyanagi M, Ozawa M (1998) Preparation of needle-like hydroxyapatite. J Mater Sci Letters 17:381-383

4. Dean-Mo L (1996) Fabrication and characterization of porous hydroxyapatite granules. Biomaterials 17:1955-1957

5. Riman RE, Suchanek WL, Byrappa K, Wei Chen C, Shuk P, Oakes CS (2002) Solution synthesis of hydroxyapatite designer particulates. Solid State Ionics 151:393-402

6. Yin G, Liu Z, Zhan J, Ding F, Yuan N (2002) Impacts of the surface charge property on protein adsorption on hydroxyapatite. Chem Eng J 87:181-186

7. Harding IS, Rashid N, Hing KA (2005) Surface charge and the effect of excess calcium ions on the hydroxyapatite surface. Biomaterials 26:6818-6826

8. Wiese GR, James RO, Yates DE, Healy TW (1976) Electrochemistry of the colloid-water interface. In: Bockris J. O'M (ed) Electrochemistry of Colloid-Water Interface, International Reviews of Science, Physical Chemistry Series 2. Butterworths, London

9. Lyklema J (1995) Fundamentals of interface and colloid science. Academic Press, London, pp 3.2-3.232

10. Fundamental the Electrical Double Layers in Colloidal Systems (1981). In: Goodwin JW (ed) Colloidal dispersions, Special Publication No 43. Royal Society of Chemistry, London

11. Rosskopfová O, Galamboš M, Rajec P (2010) Study of sorption processes of strontium on the synthetic hydroxyapatite. J Radioanal Nucl Chem 287(3):715-722

12. Rosskopfová O, Galamboš M, Ometáková J, Čaplovičová M, Rajec P (2012) Study of sorption processes of copper on synthetic hydroxyapatite. J Radioanal Nucl Chem 293(2):641-647 
13. Rosskopfová O, Galamboš M, Pivarčiová L, Čaplovičová M, Rajec P (2013) Adsorption of nickel on synthetic hydroxyapatite from aqueous solutions. J Radioanal Nucl Chem 295(1):459-465

14. Filgueiras MRT, Mkhonto D, de Leeuw NH (2006) Computer simulations of the adsorption of citric acid at hydroxyapatite surface. J Crystal Growth 294:60-68

15. Vega ED, Narda GE, Ferretti FH (2003) Adsorption of citric acid from dilute aqueous solutions by hdroxyapatite. J Colloid Interface Sci 268:37-42

16. Lopez-Macipe A, Gomez-Moralez J, Rodriguez-Clemente R (1998) The role of $\mathrm{pH}$ in the adsorption of citrate ions on hydroxyapatite. J Colloid Interface Sci 200:114-120

17. Misra DN (1998) Interaction of some alkali metal citrates with hydroxyapatite ion-exchange adsorption and role of charge balance. Colloids Surf A141:173-179

18. Bianco A, Cacciotti I, Lombardi M, Montanaro L, Gusmano G (2007) Thermal stability and sintering behaviour of hydroxyapatite nanopowders. J Therm Anal and Cal 88(1):237-243

19. Jillavenkatesa A, Condrate RA (1998) Sol \pm gel processing of hydroxyapatite. J Mater Sci 33:4111-4119
20. Skartsila P, Spanos N (2007) Surface characterization of hydroxyapatite: potentiometric titrations coupled with solubility measurements. J Colloid Interface Sci 308:405-412

21. Pang YX, Bao X (2003) Influence of temperature, ripening time and calcination on the morphology and crystallinity of hydroxyapatite nanoparticles. J Eur Ceram Soc 23:1697-1704

22. Krajewski A, Mazzocchi M, Buldini PL, Ravaglioli A, Tinti A, Taddei P, Fagnano C (2005) Synthesis of carbonated hydroxyapatites: efficiency of the substitution and critical evaluation of analytical methods. J Mol Struct 744-747:221-228

23. Tõnsuaadu K, Gross KA, Pluduma L, Veiderma M (2012) A review on the thermal stability of calcium apatites. J Therm Anal and Cal 110:647-659

24. Predoana L, Malic B, Zaharescu M (2009) $\mathrm{LaCoO}_{3}$ formation from precursors obtained by water-based sol-gel method with citric acid. J Therm Anal Cal 98:361-366 